7 Immelman K. Role of the environment in reproduction as source of "predictive" information. In: Farner DS, ed. Breeding biology of birds. Washington DC: National Academy of Sciences, 1973:121-47.

8 Hoffman K. Photoperiodism in vertebrates. In: Aschoff J, ed. Handbook of behavioural neurobiology. New York: Plenum Press, 1981:449-73.

9 Moore RY. The innervation of the mammalian pineal gland. In: Reiter RJ, ed. The pineal gland and reproduction. Basel: Karger, 1978:1-29.

10 Lewy AJ, Wehr TA, Goodwin FK, Newsome DA, Markey SP. Light suppresses melatonin secretion in humans. Science 1980;210:1267-9.

11 Hastings MH, Herbert J, Martensz ND, Roberts AC. Melatonin and the brain in photoperiodic mammals. In: Evered D, Clark D, eds. Photoperiodism, melatonin and the pineal. London: Pitman, 1985:57-77.

12 Wehr TA, Jacobson FM, Sack DA, Arendt J, Tamarkin L, Rosenthal NE. Phototherapy of seasonal affective disorder. Arch Gen Psyckiatry 1986;43:870-5.

13 Murphy D, Abas M, Checkley SA. Sensitivity to light in seasonal affective disorder. In: Thompson C, Silverstone T, eds. Seasonal affective disorder. London: CNS Neurosciences (in press).

14 Winton F, Corn T, Huson LW, Franey C, Arendt J, Checkley SA. Effects of light treatment upon mood and melatonin in patients with seasonal affective disorder. In: Thompson C, Silverstone T, eds. Seasonal affective disorder. London: CNS Neurosciences (in press).

\title{
Crisis in the National Health Service
}

On 7 December the presidents of the Royal Colleges of Physicians, Surgeons, and Obstetricians and Gynaecologists issued the following joint statement

Each day we learn of new problems in the NHS-beds are shut, operating rooms are not available, emergency wards are closed, essential services are shut down in order to make financial savings. In spite of the efforts of doctors, nurses, and other hospital staff patient care is deteriorating. Acute hospital services have almost reached breaking point. Morale is depressingly low.

It is not only patient care that is suffering. Financial stringencies have hit academic aspects of medicine in par- ticular, because of the additional burden of reduced University Grants Committee funding. Yet the future of medicine depends on the quality of our clinical teachers and research workers.

Face saving initiatives such as the allocation of $£ 30 \mathrm{~m}$ for waiting lists are not the answer. An immediate overall review of acute hospital services is mandatory. Additional and alternative funding must be found. We call on the government to do something now to save our health service, once the envy of the world.

SIR RAYMOND HOFFENBERG IAN P TODD SiR GEORge PINKER

\section{Regular Review}

\section{Community care I: problems}

\author{
ELAINE MURPHY
}

In December 1986 the Secretary of State for Social Services announced that Sir Roy Griffiths would undertake a review of community care. His report is expected early in the New Year. The announcement that Griffiths was to conduct a review caused both hopeful excitement and sceptical anxiety among professionals struggling to develop community based services for people with chronic health problems. The "nonacute" sector of the health service hopes that he will recommend innovations that will have as much impact on community services as the first Griffiths report had on National Health Service management. ${ }^{1}$ His terms of reference are "to review the way in which public funds are used to support community care policy and to advise on the options that would improve the use of these funds as a contribution to more effective community care." Sir Roy has advisers with an interest in community care and is supported by a small departmental team of administrators.

The King's Fund has meanwhile produced its own evidence and recommendations to Griffiths in the form of two memoranda, Facilitating Innovation in Community Care and Making a Reality of Community Care, which draw together the fund's wide knowledge and experience. ${ }^{23}$ Three other reports will be influential in shaping the final report: firstly, the well publicised report from the Audit Commission, Making a Reality of Community Care,${ }^{4}$ which suggests major reforms in the statutory services; secondly, the report of the Joint Working Party on Public Finance and Residential Care, Public Finance and Residential Care (the Firth report), ${ }^{5}$ which has recommended a substantial change in the way supplementary benefit is used to support 
residential care; lastly, there is the review of residential care being undertaken by Lady Wagner and a team from the National Institute of Social Work.

\section{What is community care?}

Since the 1950s governments have fostered the idea that people who suffer from long term physical or mental handicaps should be cared for elsewhere than in large institutions. Community care policies are targeted at four overlapping groups: elderly people with physical or mental disorder, chronically mentally ill people, people with mental handicap, and physically disabled younger people.

These groups have in common disorders which make the sufferers dependent on others for help with practical everyday activities, but patients have an extraordinary diversity of individual problems. An intelligent young student disabled by cerebral palsy clearly has different needs from a woman in her 80s with senile dementia and arthritis. Furthermore, most chronically disabled people have always lived outside longstay hospitals, usually in their own homes. We have had community care for centuries. The difference now is that the concept is being extended to the most seriously disabled by the closure of the large psychiatric and mental handicap hospitals and of longstay wards for the chronic sick. The policy is intended to shift care towards options ranging from care in the person's own home, through a wide variety of intermittently supervised or fully staffed lodgings and sheltered homes, to residential homes and nursing homes.

Support for this policy has become almost universal since the government's 1976 document Priorities for Health and Personal Social Services in England. ${ }^{6}$ Few now disagree with the aim of keeping disabled people in their own homes or in a "home like" environment for as long as possible, preserving consumers' right to choose the services they receive and their own clothing, meals, bedtimes, friends, and social activities. Unfortunately, this laudable aim has not worked out well in practice. The concept of the "community" providing "care" means in reality disabled people caring largely for themselves, perhaps with the help of a relative who is undertaking the care at great personal cost. ${ }^{78}$ What has gone wrong?

\section{The reality of community care}

Britain has seen a remarkable diversity of local innovative schemes_but overall progress has been haphazard and slow. The Audit Commission report pointed to some possible reasons for the failure of the policy.

\section{FOR MENTALLY HANDICAPPED PEOPLE}

Several major scandals in large mental handicap hospitals meant that implementing community care services started early with mentally handicapped people but progress has been slow. Targets were set in $1971,{ }^{9}$ and large mental handicap hospitals are being replaced by smaller residential institutions run by health or local authorities. By 1985 , however, only $21 \%$ of provision was being provided as ordinary houses and flats, although the 1971 white paper envisaged that over half the provision would be in such accommodation.
The transfer of mentally handicapped people into smaller hospitals or hostels does not necessarily improve their performance in daily skills or give them a fuller life, as a recent study by Shah and Holmes has shown, ${ }^{10}$ Where, however, mentally handicapped people have moved into ordinary accommodation and been supported with a vigorous programme of "normalisation," many former hospital patients have acquired a degree of independence and decision making that was previously thought impossible.

Many mentally handicapped people have never been in institutions and have continued to live at home with their families; their needs have been largely ignored-the focus has been placed on the run down of the institutions. Nor have services developed for those with serious behaviour disorders, coyly referred to as "persons with challenging needs." These people_-often with poorly controlled epilepsy, serious psychiatric disorder, or seriously abnormal personality traits-need regular medical assessment and a degree of supervision that is extremely expensive to provide - up to $£ 40000$ a year for each patient is normal.

\section{FOR PEOPLE WITH MENTAL ILLNESS}

Services for mentally ill people give even greater grounds for concern. While psychiatric hospital places were reduced by 25000 between 1974 and 1984, residential places provided by local authorities and the private and voluntary sector have risen by only 3200 . Nor has there been a compensating rise in day care, which has risen by only 9000 places. The tragic reality of community care for many chronically mentally ill people was graphically described by the campaigning journalist Marjorie Wallace in the Sunday Times Magazine. ${ }^{11}$

Altogether no fewer than 80000 people have been discharged from psychiatric hospitals over the past 20 years, yet little is known about what has happened to them. Health authorities did not begin to plan alternatives to longstay hospital care until the early 1980 s and by this time the patients best able to care for themselves were long gone. Those now left in hospitals, the more seriously disabled older patients who have been in hospital for 30 to 40 years, cannot just be extruded into an unwilling community, but patients with chronic illnesses who have been in hospital for less time are now rapidly discharged to inadequately supported accommodation to make room for the next acute admission.

The result is that many chronically ill people with untreated florid illness are living in seedy bed and breakfast hotels or lodging houses funded by supplementary benefit social security payments or are drifting to the inner cities to occupy hostels for single homeless people. In a recent survey in a large Salvation Army hostel in my own health district, Lewisham and North Southwark, no less than 35\% of residents had chronic schizophrenia and four out of five were experiencing hallucinations and delusions that seriously interfered with their social functioning.

The United States has similarly pursued a policy of closing the large state hospitals with disastrous consequences. A public outcry at the plight of "the crazies" in New York City led Mayor Koch to introduce emergency legislation to remove mentally ill people from the streets to proper hospitals.

A further problem has been the lack of commitment to follow up discharged patients and a failure to invest in information systems that enable us to track discharged patients and monitor progress; we simply do not properly know what becomes of them. ${ }^{12}$ 


\section{FOR ELDERLY PEOPLE}

The problems facing the services for elderly people result from the rapid growth of the very old population. There will be a $50 \%$ increase in the numbers of those over 85 in Britain between now and the end of the century, and this trend should have led to a vigorous expansion of services, although the government has never published explicit targets. The white paper Growing Older $^{13}$ exhorted authorities to keep old people at home for "as long as possible," but a lack of specific targets has resulted in equally woolly demands by regional health authorities in their annual performance review of districts. Regions simply do not clearly know what they should be aiming at, so it is scarcely surprising that district health authorities' services have remained static. Grundy's comprehensive review in the $B M \mathcal{F}$ showed that domiciliary nursing services and home care services have fallen way behind what is necessary to keep up with the demographic changes. ${ }^{14}$

Although numbers of longstay beds in geriatric hospitals declined between 1976 and 1984 along with places in local authority residential homes, the total number of residential care places has been swelled by the rapid growth of private residential care homes and nursing homes. This process began in the early 1980s, when supplementary benefit became available for supporting individuals in private care, but the bonanza in private care began in earnest in November 1983, when local DHSS offices were empowered to spend central funds based on the cost of suitable accommodation in the area. Over the next three years the number of private residential care home places increased from 40000 to 140000. The Audit Commission and others have suggested that there may be elderly people in private residential care who do not need to be there, but a recent review found little evidence of any realistic alternatives. ${ }^{15}$

\section{Variability in community care}

The variability of community care services between one area of Britain and another is considerable and does not correlate well with social and demographic factors. Whereas the inner city authority in Newcastle on Tyne spends $£ 7.43$ a year per head of population on services for the mentally ill, the wealthy London Borough of Redbridge manages 49p. The growth of the private sector has been determined largely by the availability of suitable, affordable properties for conversion. The south coast seaside resorts thus have many residential care places funded by supplementary benefit, but inner city and industrial areas, especially those in inner London, have few.

\section{Problems of funding community care}

About $16000 \mathrm{~m}$ is currently spent annually from the Exchequer in providing long term community care and domiciliary services. It goes in three separate ways.

NHS funds flow via regional health authorities to districts. Enormous sums are tied up by the large old hospitals and also in providing primary care nursing services. This method of funding makes no provision for the need to shift services to the local authorities. Health authorities are often tempted to plunder the resources unlocked by "attrition rates"-for example, the deaths of old residents-in psychiatric and mental handicap hospitals to prop up the ailing acute hospital sector, ignoring the needs of new younger chronically ill people living in the community.

The rate support grant to local authorities is distributed from the Department of the Environment and often tends to act as a deterrent to expanding community based services. Rate capping broadly deters the development of services, but allocating recent small increases in the grant that are meant to fund the community care services has been left to elected members-and their political objectives have not always favoured community care.

Social security benefit allowances, currently up to $£ 180$ a week, are paid from the DHSS through social security offices to individual claimants to enable them to buy care in residential homes. In comparison, allowances for individuals being supported at home by relatives are pitifully small, thus encouraging residential rather than domiciliary care.

\section{INFLEXIBILITY AND LACK OF COORDINATION}

These three sources of funds are, moreover, remarkably inflexible and uncoordinated, even though two are allocated by the same ministry, the DHSS. The extraordinary impact on the shape of services and the enormous demand for private residential care that came about after November 1983 seem to have taken the NHS Management Board and social services departments by surprise. At the heart of the problem may well be the complexity of the DHSS central organisation, in which, without central coordination, policy may be developed on the social security side but have a major impact on the NHS and local authorities. ${ }^{16}$

Joint finance represents about $1 \%$ of the NHS budget and was introduced in 1976. It is set aside and allocated through regions to districts and is intended specifically for expenditure on personal social services. It is intended as pump priming money, but as it tapers back after some years local authorities are increasingly reluctant to accept the long term commitments that such funding implies. It has proved an incentive to joint planning in some areas but overall has had a disappointing effect on services and has been used mainly for one off showpiece projects. The amount of joint funding is so small that it could not have an important impact.

A further problem is that while large hospitals are being run down little money is released-the real benefits accrue once the hospital actually closes. Community based services therefore need bridging finance for setting up costs, retraining staff, capital acquisitions, and so on-and such finance has not been available.

\section{Multiple organisations and confused responsibilities}

The problems of multiple organisations and confused responsibilities can be illustrated by a typical case.

$\mathrm{Mr}$ Brown, 83, is a widower living alone. He has longstanding emphysema, intermittent chest infections that often cause confusion, and poor mobility. He has not been out of the house alone for months. The services he might need at any given time are provided by several different agencies; home help and meals on wheels by the home care section of the social services department; a district nurse from the community unit in the health authority; and day care from a separate division of social services. He may rent his flat from a housing association, receive financial allowances through social security, and perhaps receive a weekly visit from a voluntary organisation. 
All these agencies will usually be separate geographically. Nobody is responsible for ensuring that $\mathrm{Mr}$ Brown's services are integrated, planned, and coordinated. If he is lucky he may have a relative capable of finding a way through the mazc of local services. A skilled social worker allocated to the case may be able through personal influence to secure the cooperation of the various local agencies and assess what is required, but in practice few people in receipt of a mixed bag of services have a permanent social worker to coordinate and monitor the package. The reality is that the agencies decide independently when to increase or decrease their input. Usually any coordination or planning of the services depends on the informal, voluntary joint working of the participating professionals, a haphazard method for delivering a reliable service.

The present management arrangements do not foster good operational planning for individual cases. Separate agencies are concerned to protect their own budgets, and there is no incentive for them to collaborate. Only in child abuse is there closer cooperation between different professionals; here a statutory responsibility has encouraged the development of explicit guidelines for joint working and for identifying individual responsibilities. Those who work with disabled people could learn much from those who work with children. Nevertheless, this closer cooperation does not solve entirely the difficulties of interagency collaboration or the desire to protect individual budgets.

\section{Joint planning problems}

Coordination of service delivery is hindered by the separate management structures within health and social services. These services not only often have different political priorities but also the joint planning system often fails to progress because of the different speeds of decision making and the different styles of accountability in the statutory authorities. NHS general managers are generally eager to see rapid progress and have the power to implement decisions quickly. Local authority staff have little delegated responsibility and must refer decisions to slow moving members' committees. In some areas, especially in the inner cities, local councillors from the far left may view their local health authority with open mistrust-a Southwark councillor, for example, described the local health authority to me as "The Condor Brigade leading Thatcher's destruction of the welfare state." When one looks at the disastrous effects of reductions in acute hospital services in inner
London, it is easy to understand how views like this gain much local credibility.

All in all, political antagonism, separate management structures, lack of coterminous boundaries between the authorities, and inadequate financial incentives often undermine completely the benefits of joint planning.

\section{The staffing problems}

Institutional care provides not only medical, nursing, and therapy skills but is also concerned with ensuring that personal care tasks for daily life are completed. In the community these services are not provided by health service staff but by the staff of local authority homes, by relatives, or, in rare cases, by a new breed of "community carer" or "support worker." Such practical hands on care is vital to providing a real alternative to long stay hospital care, yet it is scarcely mentioned in documents on manpower planning. Who these people should be, what their training needs are, and what career structure should be developed for them are largely unknown. What is not in dispute is that such people are essential.

\section{The role of the general practitioner}

Local general practitioners and family practitioner committees rarely participate in managing, planning, and delivering community care services. Yet at times of crisis they play a crucial part. Suddenly the general practitioner may be expected to pull a solution out of his medical hat, with little knowledge about the possible alternatives. All too often an emergency hospital admission is the only solution open to him. Thus general practitioners have a particular ability to intervene to end community care, a problem that is seldom recognised. Most general practitioners wish to participate more in community care and are supportive of its aims. Mechanisms for ensuring their commitment and participation are urgently required.

ELAINE MURPHY

\author{
Professor of Psychogeriatrics, \\ United Medical and Dental Schools of \\ Guy's and St Thomas's Hospitals, \\ Guy's Hospital, \\ London SE1 9RT
}

This is the first of a two part article on community care. The next part will be published in the first issue after Christmas and will discuss possible solutions to the problems of community care.
1 Department of Health and Social Security. NHS management inquiry (the Griffiths report). London: DHSS, 1983.

2 King's Fund. Facilitating innovation in communixy care. London: King's Fund, 1987.

3 King's Fund College. Making a reality of community care. London: HMSO, 1986.

4 The Audit Commission. Making a realiny of communiyy care. London: HMSO, 1986.

5 Department of Health and Social Security. Public finance and residential care. London: DHSS, 1987.

6 Department of Health and Social Security. Priorities for health and personal social services in England. London: HMSO, 1976.

7 Nissel M, Bannerjea L. Family care of the elderly. Who pays? London: Policy Studies Institute, 1982.

8 Gilleard CJ, Belford H, Gilleard E, Whittick JE, Gledhill K. Emotional distress among the supporters of the elderly mentally infirm. Br f Psychiatry 1984;145:172-7.
9 Department of Health and Social Security. Better services for the mentally handicapped. London: HMSO, 1971 .

10 Shah A, Holmes N. Locally based residential services for mentally handicapped adults: a comparative study. Psychol Med 1987;17:763-74.

11 Wallace M. A caring community. Sunday Times Magazine 1987 May 3:25-38.

12 Jones K. After hospital: a study of long term psychiatric patients in York. University of York: Department of Social Policy and Social Work, 1985.

13 Department of Health and Social Security. Growing older. London: HMSO, 1981.

14 Grundy E. Community care for the elderly, 1976-84. Br Med F 1987;294:626-9.

15 Social Policy Research Unit. Supplementary benefit residential care assessment report. University of York: Department of Social Policy and Administration, 1987.

16 Hunter DJ, Wistow G. Community care in Britain. Variations on a theme. London: King Edward's Hospital Fund for London, 1987. 